Article

\title{
Analysing the Utilisation Effectiveness of Mining Machines Using Independent Data Acquisition Systems: A Case Study
}

\author{
Jarosław Brodny ${ }^{1}(\mathbb{D})$ and Magdalena Tutak ${ }^{2, *(D)}$ \\ 1 Faculty of Organization and Management, Silesian University of Technology, 41-800 Zabrze, Poland \\ 2 Faculty of Mining, Safety Engineering and Industrial Automation, Silesian University of Technology, \\ 44-100 Gliwice, Poland \\ * Correspondence: magdalena.tutak@polsl.pl; Tel.: +48-322-372-528
}

Received: 30 April 2019; Accepted: 27 June 2019; Published: 28 June 2019

\begin{abstract}
Growing competition in the market for energy raw materials needed for power generation has led to an increasing number of measures being undertaken in the mining sector to reduce the unit costs of mining production. One of the areas that offer considerable savings in this regard is the utilisation of the technical resources owned by mines. This article is therefore focussed on analysing the utilisation effectiveness of these machines, based on the data recorded by industrial automation systems, as well as on measurements from independent surveying and chemical analysis of the excavated material's quality. For this purpose, a methodology was developed to use the data about the operational parameters of the machines in order to analyse the effectiveness of their utilisation. It was assumed that the reliability of this assessment would depend mainly on the quality of the data used to conduct it. It was also assumed that using independent data sources for the analysis would provide objective and reliable information on the operation of the machines, devoid of any subjective feelings of the personnel or other factors. The developed methodology, based on a modified Overall Equipment Effectiveness (OEE) model, was used to analyse four machines that comprise the automated longwall system. Values were determined for each machine, including their availability, performance and product quality. This, in turn, made it possible to determine a total effectiveness indicator, based on a modified Overall Equipment Effectiveness (OEE) model, for the particular machines and the entire technical systems they form. The obtained results were used to assess the effectiveness of their utilisation and recommend corrective measures aimed at improving this metric. Moreover, the analysis results made it possible to assess the utilisation status of the machines in question. They also served as the basis for determining further lines of research, the purpose of which is to improve the effectiveness of the mining sector. The obtained results indicated that this process requires the wide application of IT tools, especially for data archiving and analysis. These tools, along with the developed model and methodology based on the analysis of large volumes of digital data, are in accord with the activities related to the implementation of Industry 4.0 idea in mining. It is the authors' opinion that the material at hand should find a wide range of practical applications in supporting the management of technical resources within the mining sector.
\end{abstract}

Keywords: mining machines; OEE model; Industry 4.0; effectiveness; industrial automation systems

\section{Introduction}

In the global economy, mining belongs to a group of conservative sectors in terms of implementing innovative technical solutions, especially of an organisational nature [1-3]. In Poland, the reason for this situation can be ascribed to mining's long-term domination of the national economy and the 
problems related to a lack of investment [1,4]. As a result of these factors and others, new technical and organisational solutions in mining have been implemented much later than in other sectors.

After entering the global free energy market, where competition is very high, the mining industry must adapt to the existing rules in order to survive. The shift from conventional sources of energy, especially hard coal, which has been apparent in Europe for several years, has further intensified the economic and ecological pressure on this sector [5-7]. These factors have motivated the managers of mining enterprises to take a series of measures, including activities aimed at reducing the unit costs of production and enhancing the effectiveness of the entire process of mining production.

This has resulted in the identification of areas which offer the possibility of reducing the costs of mining production without incurring substantial investment costs. One such area is maintenance, especially in terms of increasing the utilisation effectiveness of the technical resources owned by mining enterprises. Preliminary analyses and audits have revealed that large savings are possible in this regard, which may contribute to the low-cost improvement in the entire mining production process's effectiveness [8-10]. This particularly concerns mining machines, whose performance and reliability have a significant influence on the unit costs of production [11-13].

Analyses of the utilisation effectiveness of mining machines in the literature have mainly concerned the equipment used in opencast mining [12,14-20]. These works have presented results for the operational effectiveness of loaders, excavators and crushers. The analyses conducted were based primarily on the Overall Equipment Effectiveness (OEE) model, which was adapted to the operation of these machines. On the other hand, an article in the literature presented the assessment results for the operational effectiveness of a longwall shearer from the Parvade hard coal mine (Iran) [21]. In this case, the analysis was also carried out using the Overall Equipment Effectiveness (OEE) model. Studies [22-25] have also made reference to the effectiveness of mining machines operating in both hard coal and bauxite mines. The above-mentioned publications essentially referred only to the analysis of the effectiveness for single mining machines, while the presented results indicated a low degree of utilisation of the mining machines being analysed.

Analysing the effectiveness of machine utilisation in the mining sector is therefore a difficult issue. Few publications in the literature have presented effective methods for such an analysis along with their results. This is mainly due to the extremely difficult and not entirely predictable environmental conditions in which the exploitation process is carried out. As a result, it is difficult to unequivocally assess the degree of utilisation of the machines used in mining exploitation.

A significant problem concerning the effectiveness analysis of mining machines is the selection of the appropriate research methodology. In practice, many models can be used for the quantitative assessment of the utilisation effectiveness of technical facilities and the functioning of maintenance services. The widest range of practical applications in various sectors has been demonstrated by the Overall Equipment Effectiveness (OEE) model and the organisational/technical Key Performance Indicators (KPI) model, as well as the reliability models [21,24,26-31].

Based on the analysis of these models in terms of their compatibility with the conditions in which mining operations take place and the specificity of mining machines, as well as the results of the publications mentioned, the authors decided to use the Overall Equipment Effectiveness (OEE) model, which is a quantitative tool for assessing the Total Productive Maintenance (TPM) strategy [9,11,26,32-37], to analyse the mining machines' operation. Therefore, to assess the effectiveness of mining production, research was undertaken to determine the actual utilisation degree of the machines used in mining production.

The tests focused on the machines that comprise the automated longwall system, designed for direct mining of the rock mass and transportation of the excavated material away from the working face area. This system constitutes the first link of the entire chain of machines used in mining production $[14,15]$. The longwall shearer, the armoured face conveyor, the main haulage conveyor and the crusher were assumed to have a significant impact on maintaining the continuity of this process, thereby greatly determining its efficiency and effectiveness. 
A view of the machines in question during operation is presented in Figure 1.

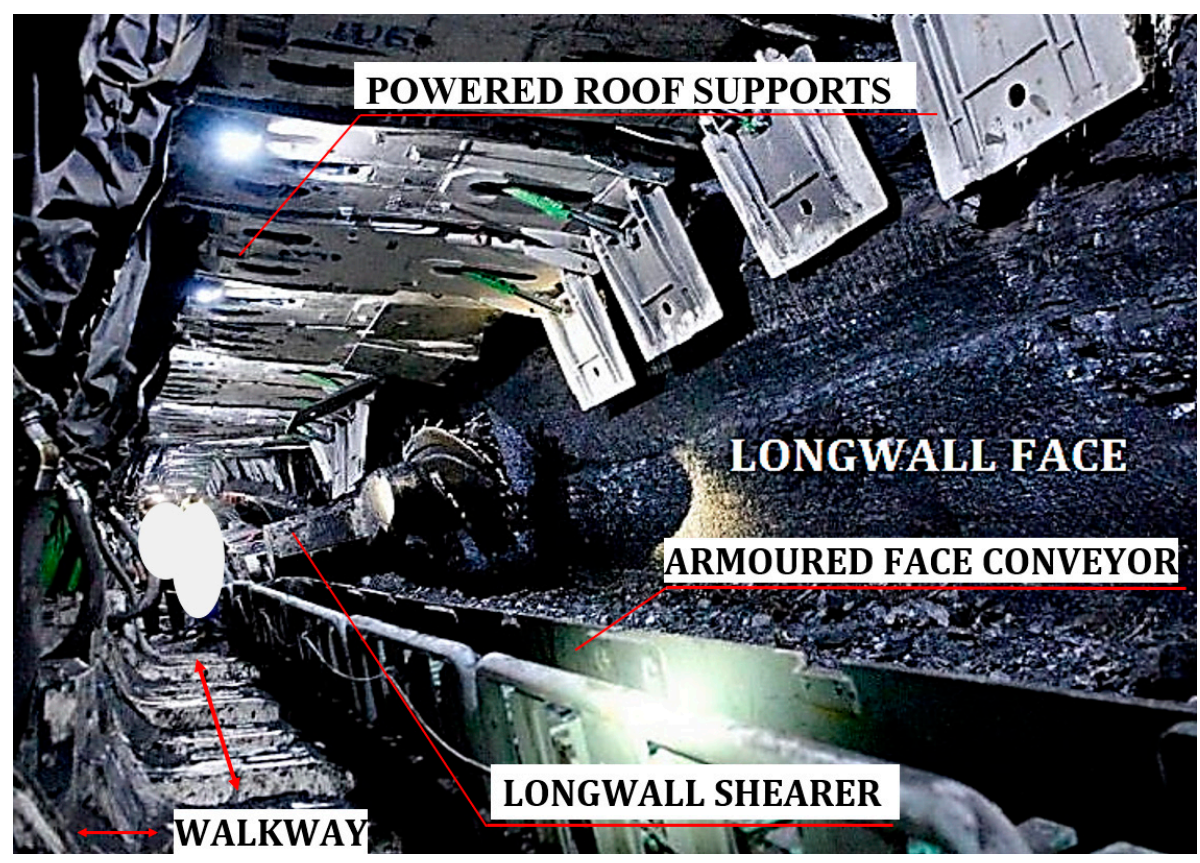

Figure 1. View at the longwall face. Reproduced from [16]. Inżynieria Górnicza, 2019.

The major mining equipment (longwall shearer, armoured face conveyor, powered roof supports) can be seen in Figure 2. At the longwall face, the shearer cuts coal from the face as it travels along the armoured face conveyor which is used for transporting coal from the face to the maingate. The coal from the longwall is then crushed by a crusher in the maingate.

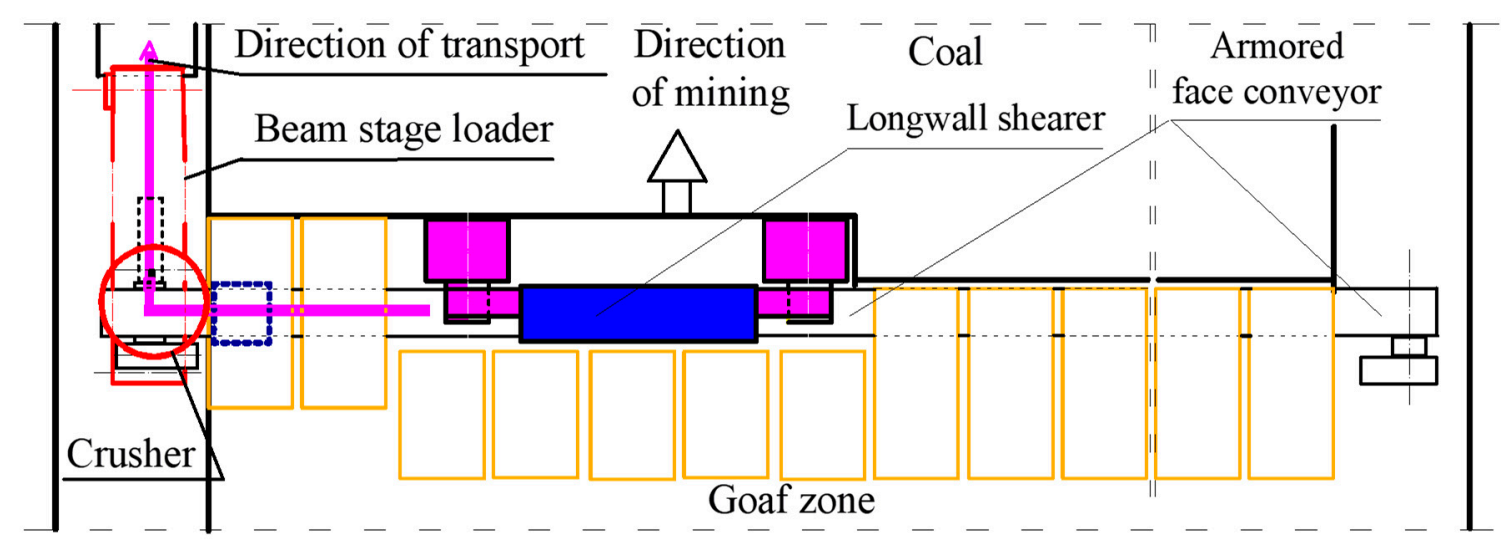

Figure 2. Diagram of the exploitation area, along with the location of the machines under analysis.

Taking into account the adopted assumptions, this article presents the results of the analysis of the utilisation effectiveness of a set of four machines that comprise the automated longwall system. The method developed was based on the effectiveness analysis of the machines being analysed in terms of their availability, performance and product quality. The base measurement used to determine the variability of all the parameters registered for the analysed machines was their operating time. Partial indicators were constructed and determined for the specific areas to analyse the machines' operation. The result of these indicators produced the final overall effectiveness indicator for each of the machines being analysed as well as for their entire set (system). The developed methodology was based on the OEE model, which was modified and adapted to the specificity of mining production. 
Irrespective of the method used, a fundamental role in this type of testing is mostly played by the reliability of the data used for the analysis. The obtained results should constitute the basis for regular effectiveness assessments of the machines being analysed, as well as for the development of guidelines on how to improve this effectiveness.

For this reason, the availability analysis presented in this paper for the machine set was carried out using the data acquired from the industrial automation system. The information about the machines' operational parameters was gathered by means of Supervisory Control and Data Acquisition (SCADA) industrial automation systems supervising the course of the exploitation process [33]. The application of this system ensured that the data were independent of the subjective feelings of the personnel as well as being automatically registered in a continuous manner. This, in turn, has made it possible to analyse the operational status of the machines based on actual and reliable data.

The main purpose of the tests, whose results are presented in this paper, was to develop a methodology to determine the utilisation effectiveness of the entire system and the particular machines that operate in an underground hard coal mine. It should be emphasised that the methodology in question represents a new approach to the issue of examining the utilisation effectiveness of mining machines, in both scientific and utilitarian aspects. This concerns the methodology developed and applied in this study and which is based on the OEE model, in addition to the acquisition, archiving and analysis of large volumes of data containing the parameters of the machines being analysed and information about their performance as well as the quality of the excavated coal material. Furthermore, an important element of the presented methodology is the development of guidelines on how to apply the knowledge gained from the analysis conducted.

The results presented in this paper encompass 13 weeks of operation of the machines that were analysed in one longwall of a hard coal mine. The analysis focused on a total of 65 working days (195 working shifts). For this period, partial indicators of availability, performance and excavated material quality were determined for the particular machines and the entire system, as well as overall effectiveness indicators.

It should also be emphasised that the tests conducted were the first ones that concerned the effectiveness of machine utilisation in the Polish coal mining industry, for which industrial automation systems, independent surveying measurements and chemical analyses were used.

The discussion about the obtained results (e.g., the reasons for the low values of the machine utilisation indicators) still requires further work. Research is also necessary to reliably identify the main factors behind the unscheduled downtimes in the operation of those machines, registered in very high numbers by the industrial automation systems.

The introduction of a methodology for determining the operational effectiveness of machines in underground mining should eventually support the management of the mining production process. This should result in an improvement of the effectiveness of this process, thereby rationalising production costs in the areas of maintaining the means of production and the entire process of mining exploitation.

\section{Materials and Methods}

The degree of machine utilisation in mining is influenced by a number of factors, including technical, organisational and mining/geological. These factors can come together in underground mine headings, resulting in a series of disruptions to the mining production process. In order to improve this situation, it is necessary to diagnose the current status and subsequently specify any relevant measures for improvement. The main assumptions behind the developed methodology were to adopt the OEE model as the basis for analysing the effectiveness of the machines under study and to focus on the data acquired from the industrial automation system and other independent sources of information about the effects of the machines' operation.

Within mining production, where the OEE methodology has not yet been applied, the analyses were concentrated in two areas. One encompassed the activities necessary to adapt the standards of 
the OEE methodology to the mining sector, taking into account its specificity. The other involved the development of tools for the practical application of IT to the adopted methodology.

As previously mentioned, a vital role in the analysis was the use of the most reliable input data possible. Therefore, industrial automation systems were used that guaranteed a practically continuous access to reliable data of sufficient quality. The analysis was based on discrete time periods of the diagnostic parameters of the machines, registered at a frequency of $1 \mathrm{~Hz}$. Independent sources of information were also used to assess the performance of the machines and the quality of the excavated coal material.

The efficiency of the exploitation process, on the other hand, was analysed using independent surveying measurements which verified the dispatcher's records. The quality of the excavated coal material was also determined on the basis of independent test results concerning its chemical composition. Using the most independent data possible was the basis of the developed methodology.

The registered periods and the acquired data served to determine the partial effectiveness indicators that encompassed the availability $(A)$, performance $(P)$ and product quality $(Q)$ for the particular machines. According to the model adopted, the product of these indicators determines the overall effectiveness indicator (for the OEE) for a given machine [17,34,35,38]:

$$
T_{\mathrm{OEE}}=\text { Availability } \times \text { Performance } \times \text { Quality } \times 100 \%
$$

The availability of the particular machines was determined using the time periods of the currents consumed by the motors of these machines. A machine was assumed not to be operating when the values of these currents were equal to "zero" or reached the values of the currents when idle. In the case of the longwall shearer, its advance speed and position in the longwall heading was also taken into account. This is because in practice, even though a longwall shearer does not directly mine the rock mass, it supports the loading process of the excavated coal material onto the armoured face conveyor. This time is then counted as the working time (runtime) of the shearer. Generally, the availability of the particular machines was determined from the following equation:

$$
\text { Availability }=\frac{\text { Normative working time }- \text { Downtime Losses }}{\text { Normative working time }} \times 100 \%
$$

The performance rate of mining machines depends on the amount of rock mass excavated. The methodology in question assumed that the performance indicator was defined as the ratio of the actual mass of the rock mass excavated (actual performance) to the mass assumed in the technical and economic plan (standard performance). Due to the fact that no direct measurements were being recorded for the mass of excavated coal material from a given longwall, the analysis was based on the data from the dispatcher's records for each of the working shifts. However, these data underwent additional verification based on surveying measurements (taken every 10 working days). In the case of discrepancies, proportionate corrections were made to the dispatcher's data for the particular working shifts. The performance rate was determined using the following equation:

$$
\text { Performance }=\frac{\text { real performance }}{\text { normative performance }} \times 100 \%
$$

Another constituent indicator of the adopted methodology was the quality of the excavated coal material. In the case of mining exploitation, the determination of this indicator requires an additional quality analysis of the excavated coal material. This paper worked on the assumption that the quality of the excavated coal material would be determined by the waste rock content in the material as well as the grade of coal obtained. The actual values of these parameters were referred to those adopted in the exploitation plan. Due to the fact that the measurements of the excavated coal material's chemical 
composition were taken once a week, the analysis was based on fixed values for a given week of the machines' operation. The quality indicator was determined based on the following equation:

$$
\text { Quality }=\frac{\text { real quality }}{\text { normative quality }} \times 100 \%
$$

The developed methodology took into consideration the specificity of mining production, in terms of determining the performance and quality indicators. This determination was subject to the realities of this process. This was because the quantity and quality of the excavated coal material are the most important results of the exploitation process as they determine the economic effectiveness of the entire mining exploitation process. It was therefore reasonable to assume that the final indicator $\left(T_{\mathrm{OEE}}\right)$ defined the utilisation degree of the standard time required to obtain high-value excavated coal material, preferably in the amount corresponding to the adopted plan.

Equations (1)-(4) shown above are general in nature.

In the case of mining exploitation, besides the three production shifts, there is an additional maintenance shift. All diagnostic and maintenance work is performed during this shift. Because no exploitation is carried out during this shift, it was not included in the effectiveness analysis. Such work should not be carried out during working shifts.

A diagram of the exploitation area, along with the location of the machines under analysis, is presented in Figure 2.

The analyses, the results of which are presented in this paper, were conducted on one longwall of a hard coal mine. The basic parameters of the analysed longwall are summarised in Table 1. Table 2, on the other hand, shows a summary of the technical parameters of the analysed machines.

Table 1. The basic mining parameters of the analysed longwall.

\begin{tabular}{cc}
\hline Seam Thickness & From $2.85 \mathbf{m}$ to $\mathbf{6 . 4 5} \mathbf{~ m}$ \\
\hline Height of the longwall & to $4.0 \mathrm{~m}$ \\
Transverse seam incline & about $6^{\circ}$ \\
Depth of the seam exploitation & $665 \mathrm{~m}$ \\
Length of the longwall & $208 \mathrm{~m}$ \\
Roof control & roof caving \\
\hline
\end{tabular}

Table 2. The technical parameters of the analysed machines.

\begin{tabular}{|c|c|c|}
\hline Mining Machines & Parameter & $\begin{array}{c}\text { Value of Parameter in Longwall } \\
\text { Conditions }\end{array}$ \\
\hline \multirow{3}{*}{ Longwall shearer } & $\begin{array}{l}\text { Maximum power installed } \\
\text { - } \quad \text { on cutting drums } \\
\text { - } \quad \text { on haulage drive } \\
\text { - } \quad \text { on hydraulic system }\end{array}$ & $\begin{array}{l}2 \times 350 \mathrm{~kW} \\
2 \times 60 \mathrm{~kW} \\
30 \mathrm{~kW}\end{array}$ \\
\hline & Haulage speed (operating) & $0-25.6 \mathrm{~m} / \mathrm{min}$ \\
\hline & Cutting drum web & $0.8 \mathrm{~m}$ \\
\hline \multirow{3}{*}{ Armoured face conveyor } & Maximum drive power & $3 \times 400 \mathrm{~kW}$ \\
\hline & Maximum capacity & $1200 \mathrm{t} / \mathrm{h}$ \\
\hline & Conveyor's length & $206 \mathrm{~m}$ \\
\hline \multirow{3}{*}{ Beam stage loader } & Maximum drive power & $1 \times 300 \mathrm{~kW}$ \\
\hline & Maximum capacity & $1200 \mathrm{t} / \mathrm{h}$ \\
\hline & Length & $60 \mathrm{~m}$ \\
\hline \multirow{2}{*}{ Crusher } & Maximum power & $2 \times 132 \mathrm{~kW}$ \\
\hline & Maximum capacity & $1200 \mathrm{t} / \mathrm{h}$ \\
\hline
\end{tabular}


In order to determine the availability of the analysed machines, the analyses were based on the registration results of their operational parameters. In the case of the longwall shearer, where the number of registered parameters was very high, the analysis was carried out using the time periods for its advance speed, the currents consumed by the motors in its cutting drums and the position of the shearer in the longwall. In the case of the remaining machines, the analyses were based on the time periods of the currents consumed by the motors in those machines.

Figure 3 presents a diagram of the shearer's data transmission system. Shearer data are transmitted from the JNA Unit 1 to the Data Module Unit. The data module converts the data received from the shearer's JNA Unit 1 into the Modbus protocol. The data is then transmitted to the third-party modem (MASTER). The third-party modem transmits the data from the shearer to the third-party equipment located in the gate end.

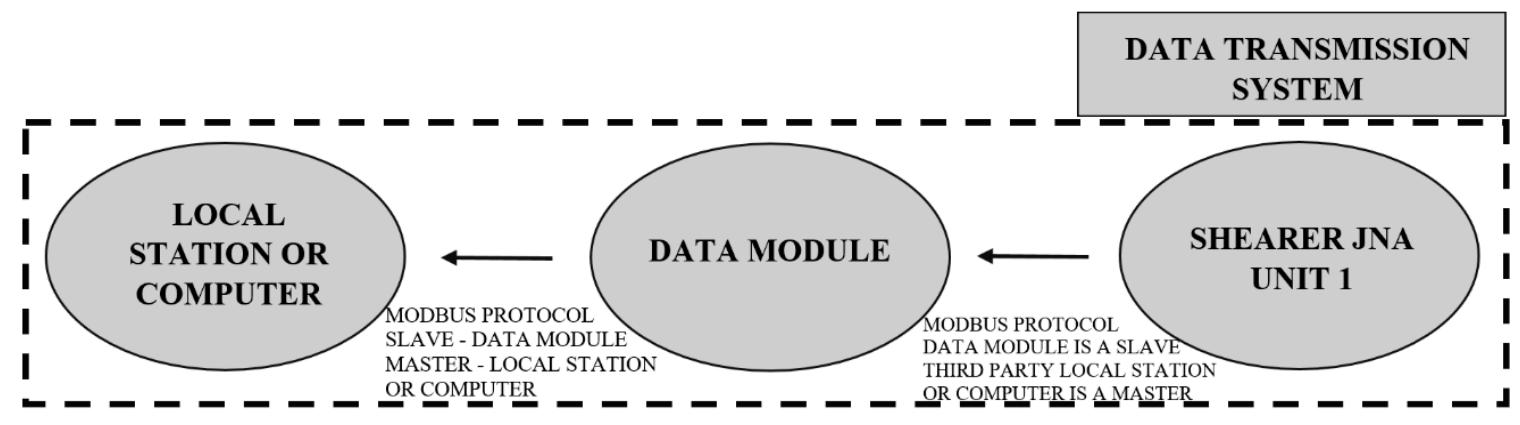

Figure 3. Diagram of the shearer's data transmission system.

The large volume of registered data required the development of IT tools that could archive and analyse such data. Relevant databases were therefore created for the particular groups and the degree of their aggregation, which were subsequently implemented into the data warehouse [17,23].

Figure 4 presents a view of the system part used for registering operation parameters in the database.

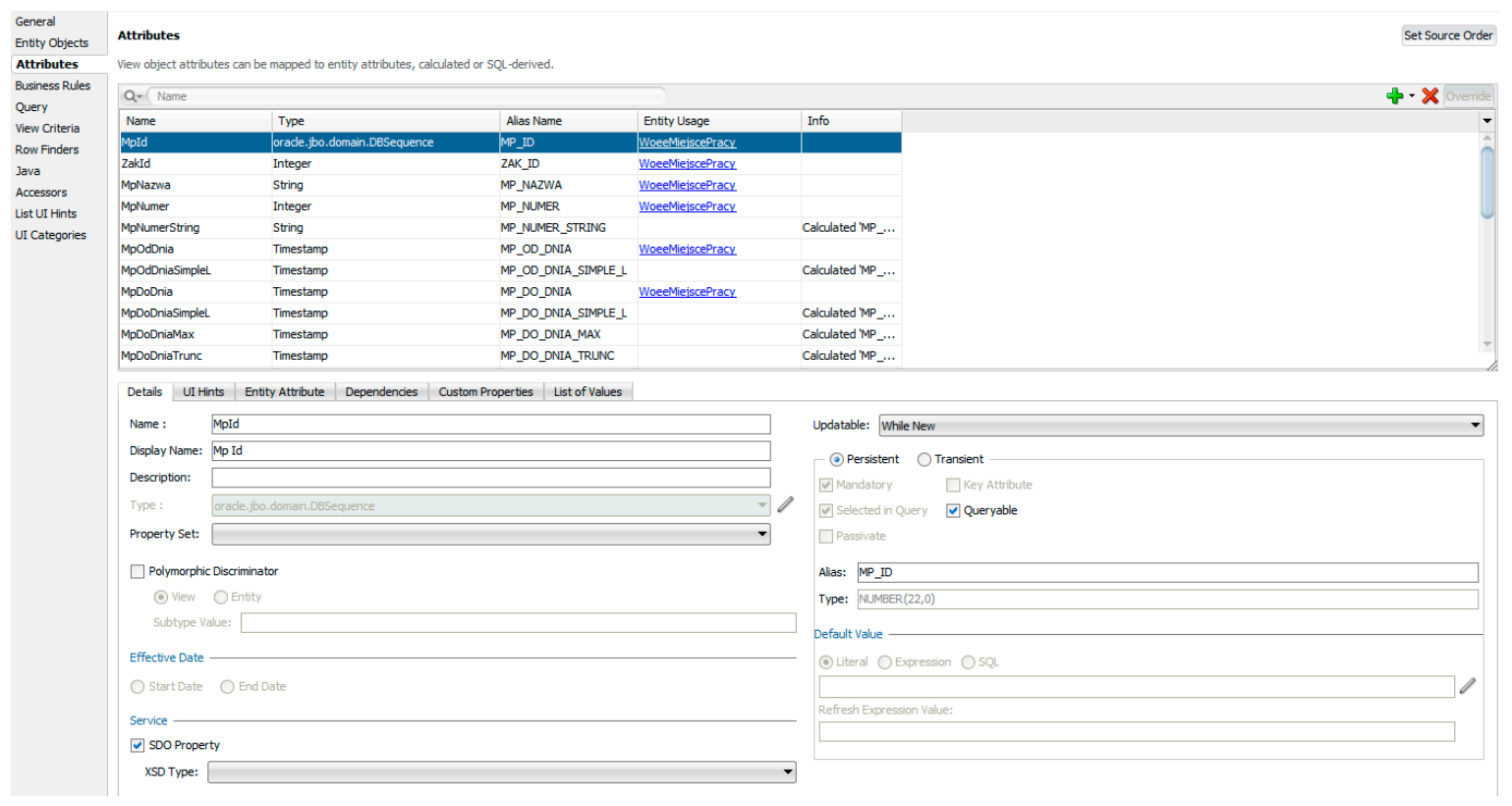

Figure 4. View of the system part used for registering operation parameters in the database. 


\section{Results and Discussion}

As has already been pointed out, the analyses encompassed four machines that comprise the automated longwall system. Each of the machines had its diagnostic parameters specified; this was essential to determine their utilisation from the perspective of the methodology applied. The parameters for each machine included the time periods of the currents used by their motors. In the case of the longwall shearer, the periods of its forward speed and its position on the longwall were also used. The time periods for the forward speed of the longwall shearer as well as its position on the longwall for one working shift are presented in Figure 5.

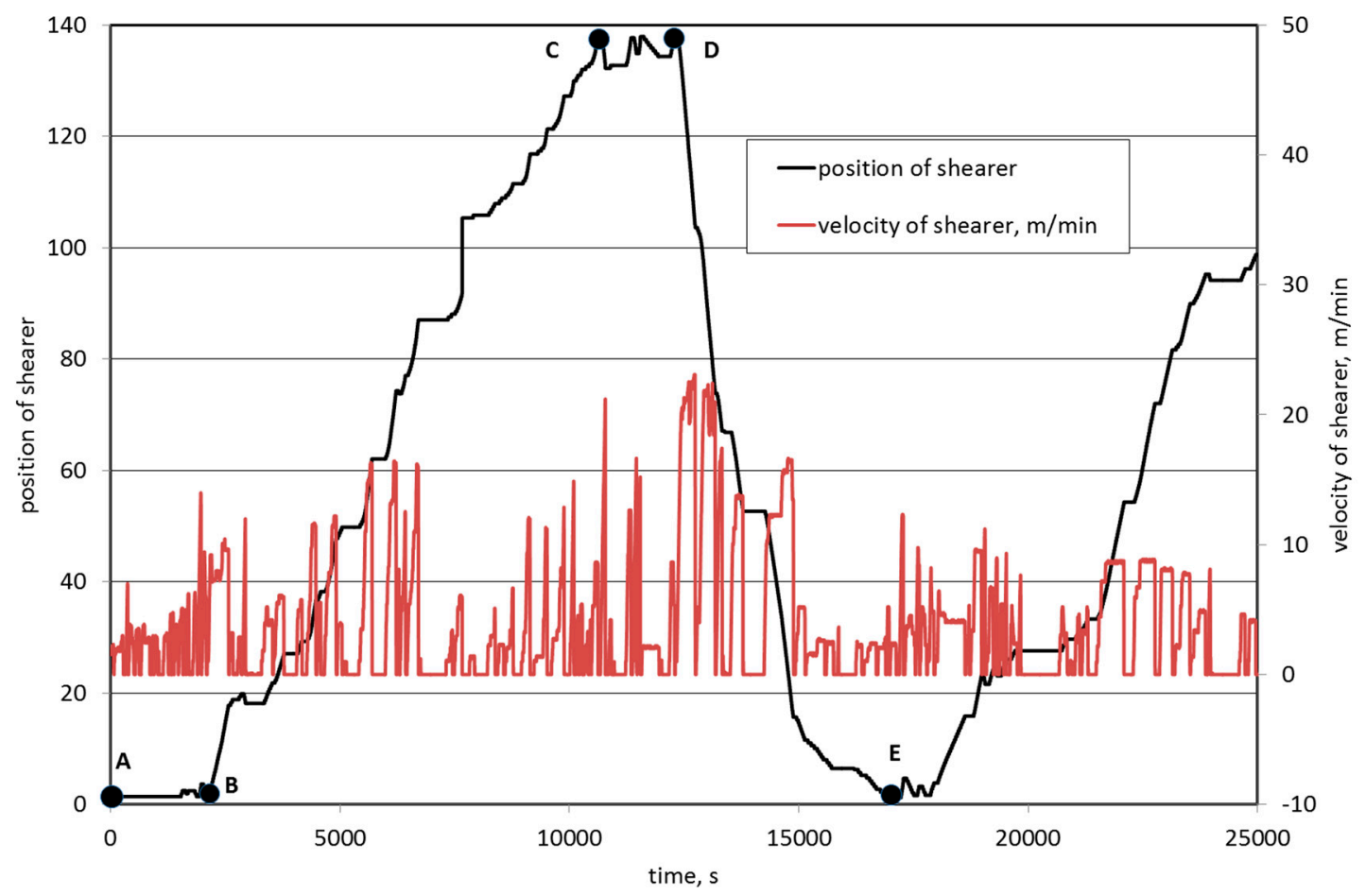

Figure 5. Time periods for the forward speed of the longwall shearer as well as its position on the longwall for one working shift.

Five characteristic points were marked on the course of the shearer's position on the longwall (relative to the section number of the powered face support) (Figure 5). The longwall being analysed was mined on a unilateral basis, which is illustrated by the marked points. Section AB denotes the movement of the longwall shearer during sumping (the beginning of excavation). Section $B C$ denotes the rock mass excavation phase, Section $C D$ refers to the manoeuvring time of the longwall shearer at the end of the longwall, while Section DE denotes the reverse travel of the shearer.

The shearer's manoeuvring time (while starting the cutting process) was treated as normal working time. Over this time, the rock mass is mined on a normal basis, which constitutes an essential part of the entire mining cycle. Analysing the time courses at hand, one may conclude that most of the unscheduled (short) downtimes occur during the process of rock mass excavation (Section $\mathrm{BC}$ ), possibly due to the problems occurring during this process. On the other hand, the stoppages during the reverse movement of the shearer (Section DE) are difficult to explain.

Figure 6 shows a small number of the registered time periods for the operational parameters of the longwall shearer. These parameters include the advance speed of the longwall shearer, its position on the longwall and the currents consumed by the motors of its cutting drums. The figure indicates selected and noticeable stoppages in the functioning of the longwall shearer, which were used to analyse its availability. This is the excavation phase of the shearer (Section BC). 


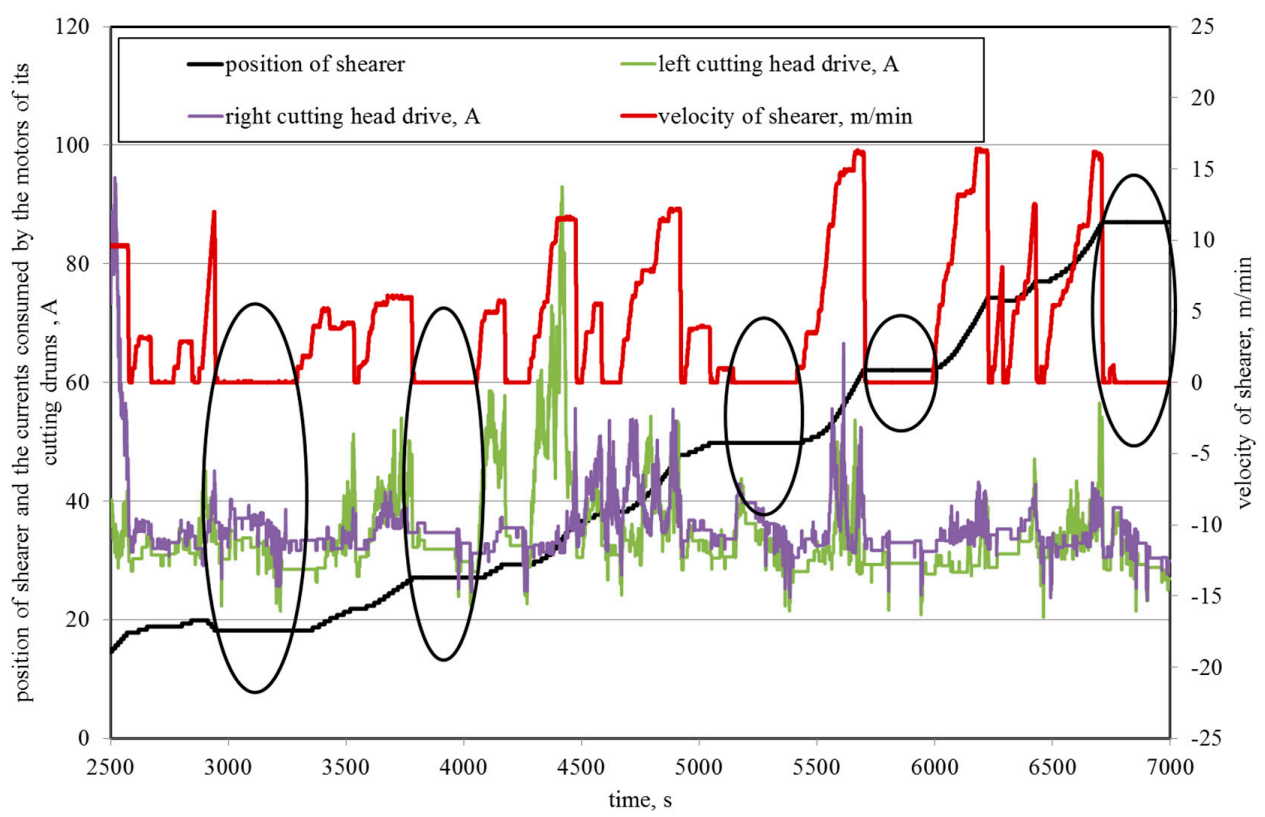

Figure 6. A small number of the registered time periods for the operational parameters of the longwall shearer.

The downtimes marked in Figure 6 are referential examples of stoppage times. Their purpose is to show sample periods of unscheduled downtimes. Besides the longest downtimes marked within this section, many shorter stoppages also occur in the shearer's operation. All were taken into consideration during the determination of availability.

In the case of the remaining machines of the system, their availability was determined using the time periods of the currents consumed by their motors. Examples of such periods for the armoured face conveyor, the main haulage conveyor and the crusher are presented in Figure 7.

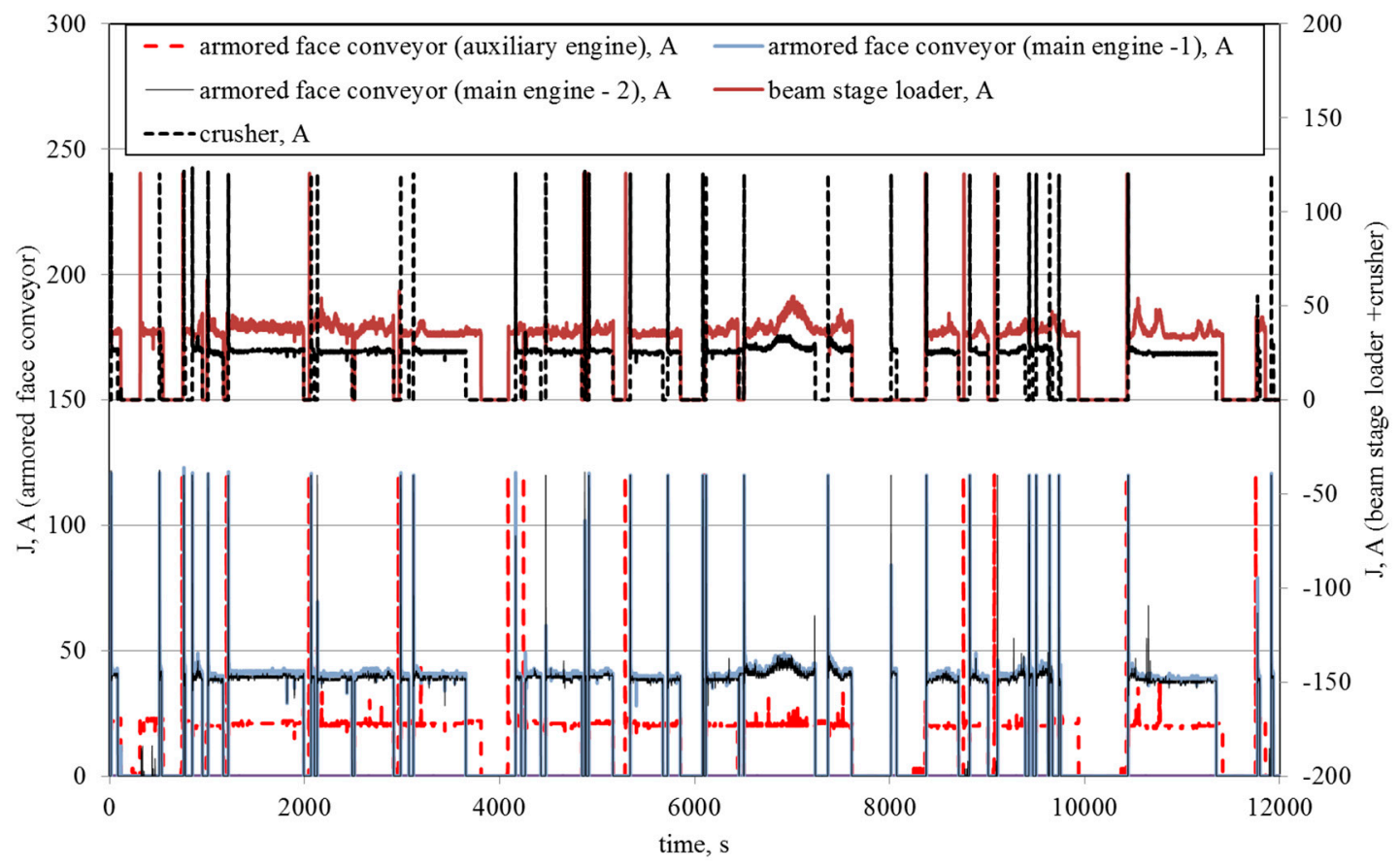

Figure 7. Time periods of the currents in the motors of the armoured face conveyor, beam stage loader and crusher. J, the currents consumed by the motors of machines. 
The time courses registered make it possible to unambiguously determine the periods of unscheduled downtimes for the machines under analysis. As mentioned before, the data were registered at a frequency of $1 \mathrm{~Hz}$. Such a registration frequency was assumed to be sufficient for the analyses in question. The time in which the machines did not consume electric current was assumed to be their downtime. The time courses determined (Figure 7) demonstrate that these downtimes most commonly affect all the machines, thereby reducing the value of the OEE indicator.

The parameters registered by the industrial automation system were used to determine the availability of the machines being analysed. Those data included the advance speed of the shearer and its position in the longwall. It must be emphasised that the availability indicator had the greatest impact on the value of the overall effectiveness indicator.

The performance rate was determined on the basis of the shift-related registration of the amount of excavation material, which was additionally verified using a surveying system. By comparing these values to those included in the technical and economic plan, it was then possible to determine this indicator for all the machines of the system.

The quality indicator, on the other hand, was determined by taking into account the measurement results of the chemical composition of the excavated coal material and its grade. This mainly concerned the waste rock content in the excavated coal material and its grain size. By comparing those results to the assumed values, it was possible to determine this indicator for all the machines of the system.

The indicators of performance and excavated coal material quality that were adopted were the same for all the machines for a given working shift. The average, maximum and minimum percentage values of the overall effectiveness indicator $\left(T_{\mathrm{OEE}}\right)$ for both the particular machines and the entire system for the test period of 13 weeks (195 working shifts) are summarised in Table 3 . The values presented refer to single working shifts.

Table 3. Comparison of the value of the total effectiveness indicators $\left(T_{\mathrm{OEE}}\right)$ for the tested machines.

\begin{tabular}{ccccc}
\hline The Tested Machines & $\begin{array}{c}\text { Average Value } \\
\mathbf{( \% )}\end{array}$ & $\begin{array}{c}\text { Variability } \\
\text { Indicator (\%) }\end{array}$ & $\begin{array}{c}\text { Maximum } \\
\text { Value (\%) }\end{array}$ & $\begin{array}{c}\text { Minimum } \\
\text { Value (\%) }\end{array}$ \\
\hline Longwall shearer & $52.52 \pm 6.21$ & 11.84 & 67.87 & 34.51 \\
Armoured face Conveyor & $57.61 \pm 6.74$ & 11.70 & 80.37 & 44.57 \\
Beam stage loader & $61.79 \pm 6.85$ & 11.09 & 70.33 & 49.72 \\
Crusher & $57.04 \pm 7.08$ & 12.42 & 78.58 & 37.38 \\
Set of machines & $57.24 \pm 7.48$ & 13.07 & 80.37 & 34.51 \\
\hline
\end{tabular}

The results indicate that the lowest value of the effectiveness indicator over the analysis period was obtained for the shearer, whereas the highest was obtained for the beam stage loader. At the same time, the analysis of the component indicators showed that the value of this indicator was mostly affected by the availability of the machines under analysis. According to the methodology developed, the values of the quality and performance indicators for the particular work shifts were the same for all the machines. As a result, it is the availability that, in this case, exercises a determining influence on the values of the overall effectiveness indicators obtained for the particular machines.

The changes in the values of the overall effectiveness indicator for the longwall shearer $\left(T_{\mathrm{OEE}(L S)}\right)$ and the entire set of machines (as average values from all the machines analysed for the particular working shifts) are presented in Figure 8.

Analysing the time courses obtained (Figure 8), one may notice a high variability in the values of the shearer's effectiveness indicator $\left(T_{\mathrm{OEE}(L S)}\right)$ for the particular work shifts. It can also be seen that, in the majority of cases, the indicator reaches values lower than the average value for all the machines under analysis. 


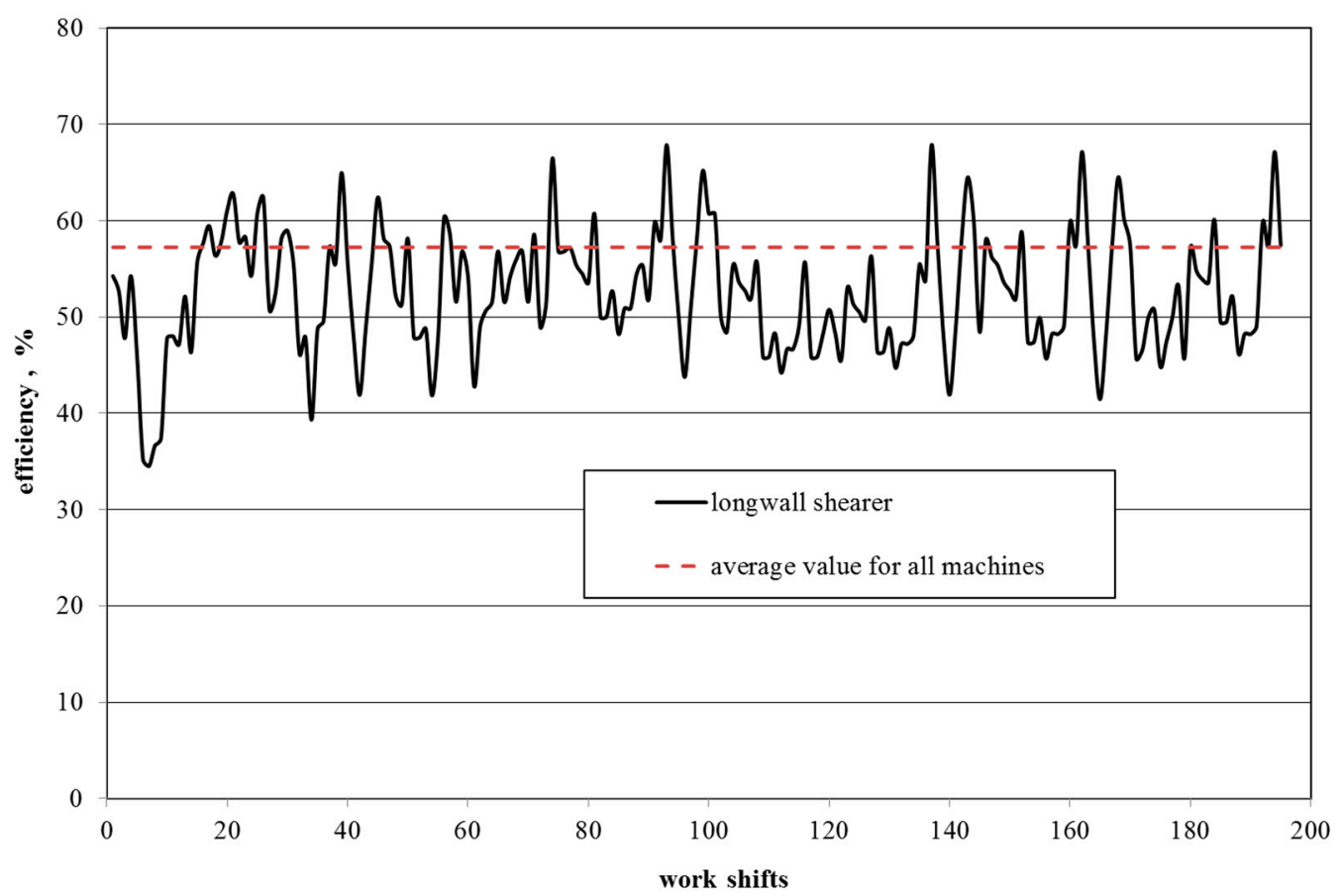

Figure 8. Changes in the values of the overall effectiveness indicator for the longwall shearer $\left(T_{\mathrm{OEE}(L S)}\right)$ and the entire set of machines (as average values from all the machines analysed for the particular working shifts).

Figure 9 presents the average values of the overall effectiveness for the machines being analysed in the particular weeks (13) of their operation (15 working shifts per week). The analysis focused on a total of 65 working days (total of 195 working shifts).

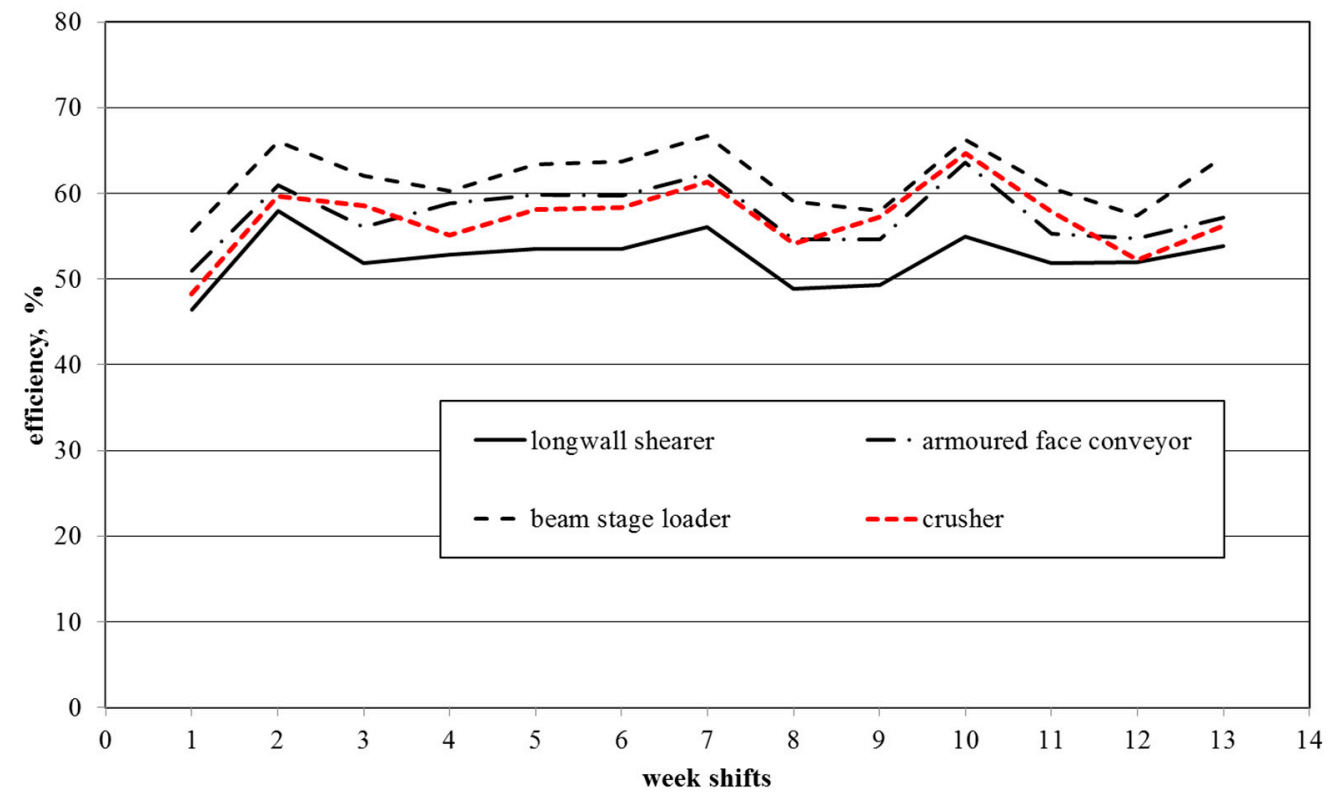

Figure 9. Average values of the overall effectiveness for the machines being analysed in the particular weeks of their operation (15 working shifts per week).

By analysing the obtained results, the authors concluded that the values of the effectiveness indicators determined for the particular machines varied greatly from one machine to another. There were also considerable differences in the values of these indicators, depending on the working shift for which they were determined. 
The parameter that had a decisive influence on the effectiveness of the analysed machines was their availability. The influence of this was particularly noticeable in the case of the longwall shearer (Figure 9). The particular working shifts were characterised by large differences in the shearer's availability, which translated into the shearer's highly diversified effectiveness (Table 3). Within the time period under analysis, the highest values of the effectiveness indicator were registered for the main haulage conveyor. Its average value for the period in question exceeded $60 \%$, which should be regarded as a good result.

High values of the indicator were also registered for the crusher, which in a number of cases was only used for oversized lumps of excavated coal material. In the specified period, as indicated by the results, it was exploited almost continuously. This suggests that the conditions in question required continuous operation of the crusher, while the effectiveness indicator obtained for the crusher was significantly higher in comparison, for example, with the shearer.

\section{Conclusions}

Growing competition in the market for energy raw materials has forced mining enterprises to reduce costs and optimise the production process in order to survive. One such measure is to improve the utilisation effectiveness of the machines owned by these enterprises. To achieve this goal, an objective assessment of the degree of utilisation for these machines must be performed. The developed methodology presented in this paper, which was based on the OEE model and diagnostic data on machine operation, has paved the way for achieving the chosen objectives.

This article presents the results of applying a new approach to the analysis of machine utilisation effectiveness in mining production. The testing methodology developed and applied in this study is based on the well-known OEE model, which constitutes a quantitative tool for assessing the TPM strategy. This model was modified in order to adapt it to the specifics of mining production. It should be borne in mind that this production was carried out in extremely difficult and not entirely predictable environmental conditions. This differed fundamentally from the case of closed enterprises where the conditions are usually well known and can be very precisely modified, depending on the requirements of the production process. In underground mining, such possibilities are either non-existent or extremely limited. The effects of mining production also differ from the products produced in other sectors, because the excavated coal material is a mass product. In the planning process of mining production, its properties can be estimated on a provisional basis only, based on mining and geological reconnaissance. It is only during direct exploitation that its quality can be assessed.

However, it seems that the approach presented in this paper has made it possible, in a quite clear and transparent manner, to assess the utilisation status of machines in mining production. The adopted model takes into account all the most important areas of this process, namely, the availability, performance and product quality for the machines.

The fundamental problem in determining the effectiveness of mining machines is the development of an appropriate methodology which can take into account the specificity of mining exploitation. In this regard, it is also necessary to take into consideration the most independent data possible. Applying the idea of constructing the OEE model made it possible to determine one indicator whose value may be reliable in the assessment of machine utilisation. It may also represent a measure to assess the changes implemented in the production process.

There is no doubt that the results obtained during the tests did not meet expectations. The average value of the overall effectiveness indicator for the specified period amounted to merely $52.52 \%$ for the longwall shearer as the most important machine of the system, which is a low value. In the case of the other machines, the values were slightly higher, yet also unacceptable, especially given the fact that no incidents were registered in the mine over the period of the analysis which could have caused more significant disruptions during the exploitation process. 
The obtained results also surprised the mining crew and the mine's management teams. This was because the existing dispatcher records did not fully reflect the actual utilisation status of the machines. As a result, the assessment of this status was extremely subjective and cursory.

The application of industrial automation systems has allowed for a very objective and reliable assessment of the utilisation rate of these machines. While developing the testing method, the authors tried to make the greatest possible use of the determined parameters, independent of the subjective feelings of the personnel. Therefore, the efficiency of production and the results of chemical analyses conducted by external bodies to assess the quality of the excavated coal material were verified using the registration results of the machines' diagnostic parameters and surveying measurements. Such an approach to the issue of the analysis of machine effectiveness made it possible, at that stage, to assess the machines in a very objective manner.

The application of the modified OEE model in mining represents a new approach to examining the effectiveness of mining machines. The results obtained prove the great potential for its application to the assessment and improvement of this effectiveness. The conclusions presented clearly demonstrate the advantages of using the proposed methodology for assessing the machine utilisation degree in mining. The utilisation of these machines was assessed so comprehensively for the first time ever, taking into consideration the three most important parameters of machine operation (i.e., availability, performance and quality).

For this paper, the manner of determining the OEE indicators was significantly modified. Although the equations used were relatively simple, the paper presented new possibilities for their application. The modification of the method for determining effectiveness demonstrated that, despite the simplicity of the equations used, the results are very interesting and may increase the effectiveness of machine utilisation.

From the perspective of the entire mining sector, this represents a significant and brand-new method for assessing the effectiveness of machine utilisation. It shows the great universality of the OEE model, which however may not be easily implemented in all sectors. In the case of mining, it had to be modified (both in the analytical aspects and in terms of the practical interpretation of results) and adapted to its specificity. In this area, it should be regarded as an important scientific contribution to the broadly conceived analysis of process effectiveness.

The method of data analysis and the manner of assessing the results obtained should also be regarded as a new approach to the assessment and, at a later stage, to the improvement in the effectiveness of machine utilisation. Such an approach has not yet been used and, in our opinion, it can be successfully applied to the broad mining sector.

Few people realise how ineffective the process of mining exploitation is in terms of the application of modern machines. The results obtained unambiguously and objectively identify this problem. So far, this problem has not been addressed to the extent presented in this article.

Only a portion of the extensive material acquired during the analysis was used in this publication. This is also true of the description and scope of the use of the IT tools which were developed to perform the analysis. The article concentrated rather on how to solve the issue of assessing machine effectiveness in such a specific sector as mining. It is the authors' opinion that the new approach to this issue presented here is appropriate to its scale and also reflects its essence. At the same time, from the obtained results and the opinions of the mining community, it has been shown that this methodology can be successfully used in the mining sector.

The methodology developed and the results obtained point to the validity of the assumptions and the necessity of conducting further research to assess their wider practical application. An essential role in this process was also played by the IT tools used to analyse these data and the IT platform, proposed as a management-support system, employed to exchange information and opinions about improving the effectiveness of the machines being operated.

However, the discussion about the obtained results (e.g., the reasons for the low values of the machine utilisation indicators) still requires further work. Research is also necessary to reliably identify 
the causes of the unscheduled downtimes in the operation of those machines, registered in high numbers by the automated systems.

The authors consider that the methodology developed and the IT tools used will find practical applications, which will improve the effectiveness and profitability of the entire process of mining production.

Author Contributions: Conceptualization, J.B.; methodology, J.B.; software, J.B.; validation, J.B. and M.T.; formal analysis, J.B. and M.T.; investigation, J.B. and M.T.; resources, J.B. and M.T.; data curation, J.B.; writing-original draft preparation, J.B. and M.T.; writing—review and editing, J.B. and M.T.; visualization, J.B.; supervision, J.B.; project administration, J.B.; funding acquisition, M.T. and J.B.

Funding: This research was funded by Ministry of Science and Higher Education, grant numbers 13/030/BK_18/0039 and 06/030/BKM_18/0041.

Acknowledgments: This article is the result of the research project No. PBS3/B6/25/2015, "Application of the Overall Equipment Effectiveness method to improve the effectiveness of the mechanized longwall system's work in the coal exploitation process", carried out in 2015-2018, financed by The National Centre for Research and Development.

Conflicts of Interest: The authors declare no conflict of interest.

\section{References}

1. Sierpińska, M.; Bak, P. Financial structure of mining sector companies during an economic slowdown. Arch. Min. Sci. 2012, 57, 1089-1100.

2. Stala-Szlugaj, K. New hard coal-mining projects in the Russian Federation. Mineral. Resour. Manag. 2013, 29 , 3. [CrossRef]

3. Stemn, E.; Bofinger, C.; Cliff, D.; Hassall, M.E. Investigating the Maturity of Incident Investigations of the Ghanaian Mining Industry and Its Effect on Safety Performance. Safety 2019, 5, 3. [CrossRef]

4. Sierpińska-Sawicz, M.; Bak, P. Costs of Corporate Bond Issue in Coal Mining Companies. Contemp. Econ. 2016, 10, 99-112. [CrossRef]

5. Helman, J. Analysis of the potentials of adapting elements of Lean methodology to the unstable conditions in the mining industry. AGH J. Min. Geoengin. 2012, 36, 151-157.

6. Brodny, J.; Tutak, M. Analysis of methane hazard conditions in mine headings. Tehnički Vjesnik/Tech. Gaz. 2018, 25, 271-276. [CrossRef]

7. Tutak, M.; Brodny, J. Degree of use of alternative sources for energy production for the economical aims in EU countries. SGEM2017 2017, 43, 635-642.

8. Brodny, J.; Tutak, M.; Michalak, M. A Data Warehouse as an Indispensable Tool to Determine the Effectiveness of the Use of the Longwall Shearer. In Proceedings of the Beyond Databases, Architectures and Structures. Towards Efficient Solutions for Data Analysis and Knowledge Representation, Ustroń, Poland, 30 May-2 June 2017; pp. 453-465. [CrossRef]

9. Stecuła, K.; Tutak, M.; Brodny, J. Application of chosen elements from japanese production and maintenance management philosophies in polish coal mines. SGEM 2017, 17, 93-100.

10. Stecuła, K.; Brodny, J.; Tutak, M. Use of intelligent informatics module for registration and assessment of causes of breaks in selected mining machines. In Proceedings of the Intelligent Systems in Production Engineering and Maintenance ISPEM 2017, Advances in Intelligent Systems and Computing, Wrocław, Poland, 28-29 September 2017; pp. 74-84. [CrossRef]

11. Lanke, A.; Hoseinie, H.; Ghodrati, B. Mine Production Index (MPI): New Method to Evaluate Effectiveness of Mining Machinery. Int. J. Environ. Chem. Ecol. Geol. Geophys. Eng. 2014, 8, 714-718.

12. Lanke, A.; Hoseinie, S.H.; Ghodrati, B. Mine production index (MPI)-extension of OEE for bottleneck detection in mining. Int. J. Min. Sci. Technol. 2016, 2, 753-760. [CrossRef]

13. Przybyła, H. Risk of mining process disruption under conditions of longwalls with high production concentration. Prz. Gór. 2009, 65, 103-106.

14. Jacobi, O. Praxis Der Gebirgsbeherrshung; Auflage, Verlag Gluckauf GmbH: Essen, Germany, 1981.

15. Peng, S.S. Longwall Mining; Syd, S., Ed.; Peng Publisher: London, UK, 2006. 
16. Inżynieria Górnicza. Available online: https://inzynieriagornicza.pl/material\%5B25441\%5D (accessed on 30 April 2019).

17. Elevli, S.; Elevli, B. Performance Measurement of Mining Equipments by Utilizing OEE. Acta Montan. Slovaca 2010, 15, 95-101.

18. Kozioł, W.; Ciepliński, A.; Machniak, Ł. Comparative analysis efficiency of work of primary machine in lignite mines-problems concerning standardization of coefficients. AGH J. Min. Geoengin. 2010, 34, 349-370.

19. Muili, A.J.; Lawal, A.I.; Aladejare, A.E. Optimization of the overall equipment efficiency (OEE) of loaders and rigid frame trucks in NAMDEB Southern Coastal Mine Stripping fleet, Namibia. Earth Sci. 2013, 2, 158-166.

20. Strempski, A.; Woźniak, J. Proposal for adaptation overall equipment effectiveness ratio OEE to assess the technical effectiveness work for basic machines in open lignite mines. Gór. Odkryw. 2017, 1, 5-10.

21. Hoseinie, S.H.; Ghodrati, B.; Kumar, U. Assessment of Reliability-Related Measures for Drum Shearer Machine, a Case Study. In Proceedings of the Sixth International Symposium High Performance Mining, Aachen, Germany, 11-12 June 2014.

22. Barabady, J.; Kumar, U. Reliability analysis of mining equipment: A case study of a crushing plant at Jajarm Bauxite Mine in Iran. Reliab. Eng. Syst. Saf. 2008, 93, 647-653. [CrossRef]

23. Fourie, H. Improvement in the overall efficiency of mining equipment: A case study. J. S. Afr. Inst. Min. Metal. 2016, 16, 275-281. [CrossRef]

24. Paraszczak, J. Understanding and assessment of mining equipment effectiveness. Min. Technol. 2005, 114, $147-151$. [CrossRef]

25. Vagenas, N.; Runciman, N.; Clément, S.R. A methodology for maintenance analysis of mining equipment. Int. J. Surf. Min., Recl. Environ. 1997, 11, 33-40. [CrossRef]

26. Brzeski, J.; Figas, M. Fundamenty TPM; Lean Vision: Wrocław, Poland, 2006.

27. Loska, A. Przegląd modeli ocen eksploatacyjnych systemów technicznych. Komputerowo Zintegr. Zarz. 2011, 2, 37-46.

28. Matejczyk, M. TPM-Sposób Na Bezawaryjność Maszyn; Wiedza i praktyka: Warszawa, Poland, 2013.

29. Melchers, R.E. Structural Reliability Analysis and Prediction; John Wiley: Chichester, UK, 1999.

30. Mobley, K.R.; Higgins, L.R.; Wikoff, D.J. Maintenance Engineering Handbook; The McGraw-Hill Companies: New York, NY, USA, 2008.

31. Polish Standard EN 15341:2007-Maintenance-Maintenance Key Preformance Indicator; British Standards Institution: Warsaw, Poland, 2007.

32. Domingo, R.; Aguado, S. Overall Environmental Equipment Effectiveness as a Metric of a Lean and Green Manufacturing System. Sustainability 2015, 7, 9031-9047. [CrossRef]

33. Daneels, A.; Salter, W. What is SCADA? In Proceedings of the International Conference on Accelerator and Large Experimental Physics Control Systems, Trieste, Italy, 4-8 October 1999; pp. 339-343.

34. Nakajima, S. Introduction to TPM: Total Productive Maintenance; Productivity Press, Inc.: New York, NY, USA, 1989.

35. Rathenshwar, S.; Dhaval, D.S.; Ashish, M.; Milesh, H.S. Overall equipment efficiency (OEE) Calculation-Automation through Hardware \& Software Development. Proced. Eng. 2013, 51, 579-584.

36. Stamatis, D.H. The OEE Primer. In Understanding Overall Equipment Effectiveness, Reliability, and Maintainability; CRC Press: New York, NY, USA, 2010.

37. Kampa, A.; Gołda, G.; Paprocka, I. Discrete Event Simulation Method as a Tool for Improvement of Manufacturing Systems. Computers 2017, 6, 10. [CrossRef]

38. Barney, M.; McCarty, T. The New Six Sigma; Prentice Hall Professional: New York, NY, USA, 2001.

(C) 2019 by the authors. Licensee MDPI, Basel, Switzerland. This article is an open access article distributed under the terms and conditions of the Creative Commons Attribution (CC BY) license (http://creativecommons.org/licenses/by/4.0/). 